\title{
A STUDY OF CORRELATION BETWEEN THE ECHOCARDIOGRAPHIC CHANGES WITH THE DURATION AND SEVERITY OF CHRONIC OBSTRUCTIVE PULMONARY DISEASE
}

\author{
J. Jain ${ }^{1}$, P. Soni², S. Apte 3 , R. Chanchlani ${ }^{4}$
}

\section{HOW TO CITE THIS ARTICLE:}

J. Jain, P. Soni, S. Apte, R. Chanchlani. "A Study of Correlation between the Echocardiographic Changes with the Duration and Severity of Chronic Obstructive Pulmonary Disease". Journal of Evolution of Medical and Dental Sciences 2014; Vol. 3, Issue 08, February 24; Page: 1997-2002, DOI: 10.14260/jemds/2014/2093

ABSTRACT: BACKGROUND: Echocardiography is the easiest way to evaluate the functions of parts of the heart like ventricles and valves. Some of the studies have shown normal echocardiography in Chronic Obstructive Pulmonary Disease (COPD) but others have shown pulmonary hypertension and cor pulmonale in most of the studies both of which are associated with decreased survival. Our study is also an effort to look for the heart changes in COPD patients and to correlate them with the duration and severity of the disease. MATERIAL AND METHODS: It was a cross-sectional study done in the Medicine department of Chirayu Medical College and Hospital, Bhopal during the period from January 2012 to June 2012. 60 cases of COPD were selected for study. Almost all the cases have varying degrees of overlapping picture of chronic bronchitis and emphysema taken as single entity of COPD. Echocardiography was done in all the 60 patients and looked for Right Atrial Enlargement (RAE), Right Ventricular Dilatation (RVD), Tricuspid Regurgitation (TR) and its severity, Right ventricular systolic pressure, and Pulmonary Arterial Hypertension (PAH). RESULTS: On Echocardiography, patients with moderate and severe grade COPD show RAE and RVD in more than $50 \%$, whereas, patients with mild grade COPD showed RAE in about $40 \%$ and RVD in about $60 \%$. In very severe grade COPD patient having TR also had severe grade PHT whereas mild grade COPD patients usually have mild grade PHT. CONCLUSION: Physicians and scientists will need to be encouraged to conduct research that will help develop newer, easier and better diagnostic methods and develop newer drugs and inhalation devices, that will not only help further improve symptoms and quality of life, but will also halt, and if possible, revert the progression of the disease.

KEYWORDS: Chronic obstructive pulmonary disease, Echocardiography, Pulmonary arterial hypertension, Right atrial enlargement, Right ventricular dilatation, Tricuspid regurgitation.

INTRODUCTION: Chronic obstructive pulmonary disease (COPD) has been defined by the presence of airways obstruction, which does not change markedly over several months and unlike asthma, is not fully reversible.1,2 Chronic cough, chronic sputum production, dyspnea and history of exposure to risk factors like tobacco smoking are the clues for the diagnosis of COPD. ${ }^{3}$ Global Initiative for Chronic Obstructive Lung Disease (GOLD) has described COPD as a disease that is preventable and curable. ${ }^{2}$ Estimates suggest that COPD will rise from the sixth rank as the cause of death in 1990 to the third rank as the most common cause of death worldwide by 2020.2-4 COPD affects pulmonary blood vessels, right ventricle, as well as left ventricle leading to development of pulmonary hypertension, cor pulmonale, right ventricular dysfunction and left ventricular dysfunction too. Echocardiography is the easiest way to evaluate the functions of different parts of the heart like ventricles and valves. ${ }^{5}$ Some of the studies have shown normal echocardiography in COPD but others have shown pulmonary hypertension and cor pulmonale in most of the studies both of which are associated with 
decreased survival.6, 7 Many studies have confirmed that echocardiographically derived estimates of pulmonary arterial pressure co-relate closely with pressures measured by right heart catheter( $r>0.7) .{ }^{8,9}$ Our study is also an effort to look for the heart changes in COPD patients and to correlate them with the duration and severity of the disease.

MATERIAL AND METHODS: This was a cross-sectional study done in the Medicine department of Chirayu Medical College and Hospital, Bhopal during the period from January 2012 to June 2012. 60 cases of COPD were selected for study. The diagnosis of COPD is based upon the clinical history, clinical examination, X-ray chest and PFT (Pulmonary Function Test). Almost all the cases have varying degrees of overlapping picture of chronic bronchitis and emphysema taken as single entity of COPD. Patients under study were thoroughly asked for age, sex, occupation, Smoking habits and sign and symptoms of COPD. Apart from the specific investigation to diagnosis of COPD routine investigation performed in each patient was CBC+ESR, Urine-routine \& microscope. Echocardiography was done in all the 60 patients and looked for RAE, Right ventricular dilatation, TR and its severity, Right ventricular systolic pressure, and pulmonary Arterial Hypertension (PAH).

DATA COLLECTION PROCEDURE: After taking written informed consent data were collected from the patients on the basis of detailed clinical evaluation and spirometry (FEV1/FVC less than 70\%). They were sent for echocardiography to cardiology department. All echocardiographies were done by the same expert cardiologist using Philips echocardiography machine and utilizing a $2 \mathrm{MHz}$ probe. The gradient between the right ventricular peak systolic pressure and right atrial pressure was measured by Doppler echo at rest in cases with tricuspid regurgitation.

The modified Bernoulli's equation was used to calculate pulmonary artery pressure (PAP). Systolic PAP ( $\mathrm{mmHg})=4 \mathrm{x}$ tricuspid systolic jet+ right atrial mean pressure. Right atrial pressure is estimated to be $5 \mathrm{mmHg}$ when the diameter of inferior vena cava is $<1.7 \mathrm{~cm}$ and a $50 \%$ decrease in the diameter with inspiration, $10 \mathrm{mmHg}$ when IVC is $>1.7 \mathrm{~cm}$ with a normal inspiratory collapse $>$ $50 \%$, and $15 \mathrm{mmHg}$ when IVC is $>1.7 \mathrm{~cm}$ and inspiratory collapse is $<50 \%$ ) 7 . When systolic PAP is more than $30 \mathrm{mmHg}$ then pulmonary hypertension (PH) is established. Right ventricular free wall thickness and cavity dilatation were measured using 2D echo. Patients were categorized into mild, moderate and severe PAH having 30-49 $\mathrm{mmHg}$, 50-69 $\mathrm{mmHg}$ and $\geq 70 \mathrm{mmHg}$ pressure respectively. Mild left ventricular disturbances were present but were not mentioned in the study.

RESULTS: Out of 60 patients, maximum number of patients is in age group 51-60 (36.67\%). Mean age is 53 years. There is male predominance over females in this study, showing a ratio of 5:1. Maximum numbers of patients have duration of illness of 5-10 years (33-33\%) closely followed by 10-20 years (30\%). Mean duration of illness is 12.7 years (Table no. 1). Smoking habits in males having COPD are 20 times more than in females, though COPD patients who are non-smokers are almost equal. Cough with expectoration is the predominant symptom in $>80 \%$ of COPD patients (Table no. 2). On clinical examination - Coarse crackles are found in $>90 \%$ of the patients followed by cyanosis, edema $\&$ hepatomegaly in about $50 \%$ of the patients (Table no. 3). COPD patients of less than 5 yrs. duration usually have mild PHT while of more than 20 yrs. duration usually have moderate to severe PHT (Table no. 4). In very severe grade COPD patient having TR also had severe grade PHT whereas mild grade COPD patients usually have mild grade PHT (Table no. 5). On Echocardiography, patients with 
moderate and severe grade COPD show RAE and RVD in more than 50\%, whereas patients with mild grade COPD show RAE in about $40 \%$ and RVD in about 60\% (Table no. 6).

DISCUSSION: A study of Echocardiography in 60 patients primarily suffering from chronic obstructive pulmonary disease (COPD) is done. In present study Cough with expectoration is the predominant symptom in $>80 \%$ of COPD patients followed by fever $80 \%$ and breathlessness $66.6 \%$. Coarse crackles are found in $>90 \%$ of the patients followed by cyanosis, edema $\&$ hepatomegaly in about $50 \%$ of the patients whereas in the study of Sharma R et.al. done in 2013 in Moradabad cough with expectoration was found in all patients, breathlessness was present in $95 \%$ of cases, clubbing in 6 patients, pedal edema in 16 cases. ${ }^{10}$

In our study we observed that 18 patients had mild pulmonary hypertension, 10 patients had moderate pulmonary hypertension and 6 patients had severe pulmonary hypertension whereas in another study done by Gupta NK, Agarwal RK, Shrivastava AB and VED ML in Rajasthan, 10 patients had mild pulmonary hypertension and 4 patients had moderate pulmonary hypertension and 3 patients had severe pulmonary hypertension. ${ }^{11}$

When COPD severity is compared with the severity of the PHT we found that out of total 24 patients of mild COPD 12 patients had mild PHT and 2 had moderate PHT, out of total 30 patients of moderate COPD 6 patients had mild PHT and 10 had moderate PHT and 1 had severe PHT, out of total 5 patients of severe COPD, 3 patients had moderate PHT and 2 had severe PHT and the 1 patient who had very severe COPD also had severe PHT. These findings were similar to the study done by Gupta NK, Agarwal RK, Shrivastava AB and VED ML in Rajasthan. ${ }^{11}$

In our study, out of total 24 patients of mild COPD; RAE, RVD and TR was observed in $10(41.6 \%), 16(66.6 \%)$ and $14(58.3 \%)$ respectively. Out of total 30 patients of moderate COPD; RAE, RVD and TR was observed in 16(53.3\%), 20(66.6\%) and 18(60\%) respectively. Out of total 5 patients of severe COPD; RAE, RVD and TR was observed in 3(60\%) patients. One patient who had very severe COPD; RAE, RVD and TR all were observed, whereas in another study done by Roshke K, Orth M, Kushcha M, Dushna HW in Pakistan, Cor pulmonale was found in 17(32.7\%) patients and Tricuspid regurgitation (TR) was recorded in 34 patients which was classified into mild TR in $20(58.8 \%)$ moderate TR $4(11.7 \%)$ and severe TR in $10(29.4 \%)$ patients. ${ }^{12}$

CONCLUSION: COPD is now a much better understood disease than before. Most COPD patients do not die because of the lung disease, but because of the other co-morbid conditions that accompany COPD. Physicians and scientists will need to be encouraged to conduct research that will help develop newer, easier and better diagnostic methods and develop newer drugs and inhalation devices, that will not only help further improve symptoms and quality of life, but will also halt, and if possible, revert the progression of the disease.

\section{REFERENCES:}

1. Innes JA, Reid PT. Respiratory disease: Chronic Obstructive Pulmonary Disease (COPD). In Boon NA, Colledge NR, Walker BR, Hunter JAA, editors. Davidson's Principles and Practice of Medicine (20th Ed). Edinburg: Churchill Livingstone Elsevier 2006; 678-84.

2. Global Initiative for Chronic Obstructive Lung Disease. Global strategy for the diagnosis, management and prevention of chronic obstructive pulmonary disease. Executive summary. Medical Communications Resources, Inc 2007; 1-43. 
3. Lopez AD, Murray CC. The global burden of disease, 1990- 2020. Nature Med 1998; 4: 1241-3.

4. Reilly JJ, Silverman EK, Shapiro SD. Chronic obstructive pulmonary disease. In Kasper DL, Braunwald E, Fauci AS, Hauser SL, Longo DL, Jameson JL, editors. Harrison's Principles of Internal Medicine (16th ed.). New York: McGraw-Hill Medical Publishing Division 2005; 154754.

5. Daniels LB, Krummen DE, Blanchard DG. Echocardiography in pulmonary vascular disease. Cardiol Clin. 2004; 22:383-99.

6. Macnee W. Pathophysiology of cor pulmonale in chronic obstructive pulmonary disease. Part One. Am J Respire Crit Care Med. 1994; 150:833-52.

7. Murphy ML, Adamson J, Hutcheson F. Left ventricular hypertrophy in patients with chronic bronchitis and emphysema. Ann Intern Med. 1974; 81:307-13.

8. Yock PG, Popp RL. Noninvasive estimation of right ventricular systolic pressure by Doppler ultrasound in patients with tricuspid regurgitation. Circulation 1984; 70:657-62.

9. Tramarin R, Torbicki A, Marchandise B, Laaban JP, Morpurgo M. Doppler echocadiographic evaluation of pulmonary artery pressure in chronic obstructive pulmonary disease. A European multicenter study. Eur Heart J 1991; 12; 103-11.

10. Sharma RA, Hashim Z, Sharma E, Hashim T, Sharma T. Diagnosis of severity of COPD on the basis of electrocardiogram. Indian Journal of Basic \& Applied Medical Research; March 2013: Issue-6, Vol.-2, P. 527-530.

11. Gupta NK, Agarwal RK, Shrivastava AB and VED ML. Echocardiographic evaluation of heart in chronic obstructive pulmonary disease patient and its correlation with the severity of the disease. Lung India. Vol 28. Issue 2. 2011.

12. Roshke K, Orth M, Kushcha M, Dushna HW. Pulmonary diseases and heart function. Internist (Berl).2007; 48(3):276-82.

\begin{tabular}{|l|c|c|}
\hline $\begin{array}{c}\text { Duration } \\
\text { of illness }\end{array}$ & $\begin{array}{c}\text { No. of } \\
\text { patients }\end{array}$ & $\begin{array}{c}\text { Percentage } \\
\text { (\%) }\end{array}$ \\
\hline$<5$ yrs. & 12 & 20.00 \\
\hline $5-10$ yrs. & 20 & 33.33 \\
\hline $10-20$ yrs. & 18 & 30.00 \\
\hline$<20$ yrs. & 10 & 16.67 \\
\hline
\end{tabular}

Table 1: Distribution of the patients

according to the duration of the illness

\begin{tabular}{|l|c|c|}
\hline \multicolumn{1}{|c|}{ Symptoms } & No. of patients & Percentage (\%) \\
\hline Cough with expectoration & 50 & 83.33 \\
\hline Breathlessness & 40 & 66.67 \\
\hline Cough + Breathlessness & 36 & 60.00 \\
\hline Chest pain & 10 & 16.67 \\
\hline Fever & 48 & 80.00 \\
\hline \multicolumn{2}{|c|}{ Table 2: Distribution of the patients according to } \\
the presenting symptoms of the illness (multiple responses)
\end{tabular}




\section{ORIGINAL ARTICLE}

\begin{tabular}{|l|c|c|}
\hline \multicolumn{1}{|c|}{ Clinical Signs } & No. of patients & Percentage (\%) \\
\hline Pallor & 20 & 33.33 \\
\hline Cyanosis & 30 & 50.00 \\
\hline Edema & 30 & 50.00 \\
\hline Hepatomegaly & 30 & 50.00 \\
\hline Raised JVP & 20 & 33.33 \\
\hline Crackles & 56 & 93.33 \\
\hline Poor air entry & 12 & 20.00 \\
\hline Signs of hyperinflation & 36 & 60.00 \\
\hline \multicolumn{2}{|c|}{ Table 3: Distribution of the patients according to } \\
the clinical signs of the illness (multiple responses) \\
\hline
\end{tabular}

\begin{tabular}{|l|c|c|c|}
\hline Duration of Illness & $\begin{array}{c}\text { Mild PHT } \\
\text { n (\%) }\end{array}$ & $\begin{array}{c}\text { Moderate PHT } \\
\text { n (\%) }\end{array}$ & $\begin{array}{c}\text { Severe PHT } \\
\text { n (\%) }\end{array}$ \\
\hline$<5$ yrs. $(\mathrm{n}=12)$ & $04(33.3 \%)$ & $0(0)$ & $0(0)$ \\
\hline $5-10$ yrs. $(\mathrm{n}=20)$ & $10(50.0 \%)$ & $02(10.0 \%)$ & $0(0)$ \\
\hline $10-20$ yrs. $(\mathrm{n}=18)$ & $04(22.2 \%)$ & $06(33.3 \%)$ & $02(11.1 \%)$ \\
\hline$<20$ yrs. $(\mathrm{n}=10)$ & $00(00.0 \%)$ & $02(40.0 \%)$ & $04(40.0 \%)$ \\
\hline
\end{tabular}

\section{Table 4: Distribution of the patients according to the duration} of the illness and severity of pulmonary hypertension

\begin{tabular}{|l|c|c|c|c|}
\hline \multirow{2}{*}{ FEV1 } & \multirow{2}{*}{ n (\%) } & \multicolumn{3}{|c|}{ Severity of PHT } \\
\cline { 3 - 5 } & & Mild & Moderate & Severe \\
\cline { 3 - 5 } & n (\%) & n (\%) & n (\%) \\
\hline$<30 \%$ (very severe) & $01(1.6)$ & $0(0)$ & $0(0)$ & $01(100)$ \\
\hline $30 \%-49 \%$ (severe) & $05(8.3)$ & $0(0)$ & $03(60)$ & $02(40)$ \\
\hline $50 \%-79 \%$ (moderate) & $30(50)$ & $06(20)$ & $10(33.3)$ & $01(6.6)$ \\
\hline$>80 \%$ (mild) & $24(40)$ & $12(50)$ & $02(8.3)$ & $0(0)$ \\
\hline & Table 5: Distribution of the patients according \\
to the FEV1 and severity of PHT
\end{tabular}

\begin{tabular}{|l|c|c|c|c|}
\hline \multirow{2}{*}{\multicolumn{1}{|c|}{ FEV1 }} & \multirow{2}{*}{$\mathbf{n}(\%)$} & \multicolumn{3}{|c|}{ ECHO } \\
\cline { 3 - 5 } & & RAE & RVD & TR \\
\cline { 3 - 5 } & & $\mathbf{n ~ ( \% ) ~}$ & $\mathbf{n ~ ( \% ) ~}$ & $\mathbf{n ~ ( \% ) ~}$ \\
\hline$<30 \%$ (very severe) & $01(1.6)$ & $01(100)$ & $01(100)$ & $01(100)$ \\
\hline $30 \%-49 \%$ (severe) & $05(8.3)$ & $03(60)$ & $03(60)$ & $03(60)$ \\
\hline $50 \%-79 \%$ (moderate) & $30(50)$ & $16(53.3)$ & $20(66.6)$ & $18(60)$ \\
\hline$>80 \%$ (mild) & $24(40)$ & $10(41.6)$ & $16(66.6)$ & $14(58.3)$ \\
\hline
\end{tabular}

Table 6: Distribution of the patients according to the severity of the FEV1 and ECHO findings 


\section{ORIGINAL ARTICLE}

\section{AUTHORS:}

1. J. Jain

2. P. Soni

3. S. Apte

4. R. Chanchlani

\section{PARTICULARS OF CONTRIBUTORS:}

1. Associate Professor, Department of Medicine, Chirayu Medical College and Hospital, Bhopal.

2. Assistant Professor, Department of Medicine, Chirayu Medical College and Hospital, Bhopal.

3. Associate Professor, Department of Medicine, Chirayu Medical College and Hospital, Bhopal.

4. Associate Professor, Department of Surgery, Chirayu Medical College and Hospital, Bhopal.
NAME ADDRESS EMAIL ID OF THE CORRESPONDING AUTHOR:

Dr. Roshan Chanchlani, 1/6 - Idgah Kothi, Doctors Enclave, Near Filter Plant, Idgah Hills, Bhopal - 462001, Madhya Pradesh. E-mail: roshanchanchlani@gmail.com

Date of Submission: 01/02/2014. Date of Peer Review: 03/02/2014. Date of Acceptance: 07/02/2014. Date of Publishing: 21/02/2014. 